\title{
POLÍTICAS DE INCLUSÃO ESCOLAR NA PERSPECTIVA DOS SETORES DE EDUCAÇÃO ESPECIAL DE TRÊS MUNICÍPIOS CAPIXABAS ${ }^{1}$
}

\author{
SCHOOL INCLUSION POLICIES FROM PERSPECTIVE OF SPECIAL EDUCATION \\ DIRECTORS IN THREE CITIES OF ESPÍRITO SANTO STATE
}

\author{
Reginaldo Celio Sobrinho ${ }^{2}$ \\ Edson Pantaleão ${ }^{3}$ \\ Denise Meyrelles de Jesus ${ }^{4}$
}

\begin{abstract}
Resumo
Sistematiza reflexões sobre as políticas de inclusão escolar em três municípios capixabas São Mateus, Vitória e Vila Velha - envolvidos em um estudo comparado internacional. Reúne discussões extraídas dos grupos focais realizados entre os meses de abril e junho de 2015, objetivando compreender como as equipes dos setores de educação especial pensam e realizam a política educacional, tendo em vista o acesso e a permanência dos estudantes com deficiência nas escolas de ensino comum. Discutimos os dados a partir da literatura que versa sobre políticas e gestão educacional, associado a uma perspectiva histórico-sociológica que compreende que qualquer ação individual decorre de processos sociais em andamento. Observa-se a pertinência de uma administração compartilhada e a premência de os gestores públicos de Educação Especial investirem na instituição de espaços coletivos de formação que impulsionem reflexões sobre a escola e sua intencionalidade política, bem como sobre a sociedade e sobre o conhecimento.
\end{abstract}

Palavras-chave: Inclusão escolar. Políticas educacionais. Educação Especial. Gestão educacional.

\footnotetext{
Abstract

It systematizes reflections on school inclusion policies in three cities of Espírito Santo StateSão Mateus, Vitória e Vila Velha - which are involved in a compared international study. It

${ }^{1}$ Estudo financiado pelo Conselho Nacional de Desenvolvimento Científico e Tecnológico - CNPq.

${ }^{2}$ Doutor em Educação, professor adjunto IV, docente do quadro permanente do Programa de Pós-Graduação em Educação, Centro de Educação/ Universidade Federal do Espírito Santo. Líder do grupo de pesquisa: Políticas, Gestão e Inclusão Escolar: contextos e processos sociais. Bolsista PNPD/CAPES/UFGD. E-mail: reginaldo.celio@ufes.br

${ }^{3}$ Doutor em Educação, professor adjunto IV, docente do quadro permanente do Programa de Pós-Graduação em Educação, Centro de Educação/ Universidade Federal do Espírito Santo. Líder do grupo de pesquisa: Políticas, Gestão e Inclusão Escolar: contextos e processos sociais. Bolsista CNPq PDJ/UFRGS. E-mail: edpantaleao@hotmail.com

${ }^{4}$ Doutora em Educação, professora Titular, docente do quadro permanente do Programa de Pós-Graduação em Educação, Centro de Educação/ Universidade Federal do Espírito Santo. Líder do grupo de pesquisa: Educação Especial: formação de profissionais, práticas pedagógicas e políticas de inclusão escolar. E-mail: Jesusdenise@hotmail.com
} 
also gathers discussions obtained from focal groups performed between april and june, 2015, aiming to comprehend how the directors team of special education think and perform the educational policy concerning the access and permanence of handicapped students in common teaching schools. We have discussed the data from the literature which deals with policies and educational management associated with a historical and sociological perspective which realizes that any individual action derives from ongoing social processes. One can observe the pertinence of a shared administration and the special education public directors' urgency on investing on collective formation institutions that impel reflections on school and its political intentionality, as well as on society and also on knowledge.

Keywords: School inclusion. Educational policies. Special Education. Educational management.

\section{Introdução}

Em diferentes países, as reformas políticas implementadas, principalmente a partir da década de 1990, colocaram a administração pública estatal como instância de elaboração e de execução de ações que estruturam o oferecimento de educação formal a uma parcela significativa da população.

Mais de duas décadas se passaram e as práticas de administração dos sistemas de ensino ainda constituem uma importante pauta de discussão e de encaminhamentos, sobretudo no que se refere ao enfrentamento das desigualdades educativas, por meio de reformas e de políticas educacionais mais inclusivas. Nesse importante aspecto, vale considerar que o caráter prescritivo e centralizador que, historicamente, caracterizou administração pública em território brasileiro, traz evidente ressonância nos modos de atuação dos entes federados, particularmente no âmbito dos municípios e dos Estados que, desde a LDBN 9394/96, assumiram a tarefa de universalizar o Ensino Fundamental (COSTA; SZATKOSKI, 2015; CURY; FERREIRA, 2010). Nesse processo, é que “[...] muitas administrações municipais preocuparam-se somente com o ato de ajustar-se para realizar o "tema de casa", ao invés de refletir a respeito da política educacional [...]”. (COSTA; SZATKOSKI, 2015, p. 170).

De fato, muitas realidades, associando-se a estudos que pensam a administração das instituições públicas na perspectiva gerencialista ${ }^{5}$, desenvolvem ações estratégicas baseado na premissa de que somente uma liderança forte reúne condições para organizar os serviços, os

\footnotetext{
${ }^{5}$ Vale destacar que a adoção dessa perspectiva gerencialista supõe "[...] a introdução de técnicas e práticas das organizações privadas no âmbito da administração pública, a fim de atingir objetivos preestabelecidos com mais eficiência, economia e eficácia". (ARRUDA; NÓBREGA, 2013, p. 32).
} 
produtos e os processos para atender ao conjunto de necessidades dos cidadãos destinatários, conforme os recursos disponíveis.

Fundamentados nessa perspectiva gerencialista, Sarmento, Menegat e Ramirez (2015) acreditam que a gestão das políticas públicas não logrará eficácia atuando baseado na "tentativa e erro" e/ou pautada exclusivamente nas experiências prévias dessas organizações. Compreendem o "Modelo de Excelência em Gestão Pública" (BRASIL, 2006), como referência para a organização de qualquer instituição pública, incluindo-se aí, as Secretarias de Educação e seus setores. Para eles, o "Modelo de Excelência em Gestão Pública" configura-se como "[...] elemento fundamental para a concretização da Missão, da Visão e dos objetivos de qualquer instituição [...]” (SARMENTO; MENEGAT; RAMIREZ, 2015, p. 315). Complementarmente asseveram que, “[...] é da Secretaria Municipal de Educação que saem as normativas e demais procedimentos administrativos e pedagógicos a serem observados pelos gestores de cada escola, de forma a se efetivar o que preconizam os dispositivos legais nacionais [...]”, desse modo, para eles, é fundamental que cada um dos gestores que atua nessa organização, “[...] possua um conjunto de conhecimentos, de técnicas e procedimentos que viabilizem agir e tomar decisões de forma a garantir uma gestão eficiente e eficaz, cujo foco seja o alcance de determinados resultados". (SARMENTO; MENEGAT; RAMIREZ, 2015, p. 328).

É importante ter em vista que os pressupostos do gerencialismo alcançaram grande repercussão em território brasileiro durante a década de 1990, momento político profundamente marcado pelo ideário neoliberal que depositava no modelo gerencial a crença de que, pela sua adoção, o nosso país entraria no rumo da modernização almejada. (COSTA; SZATKOSKI, 2015).

Todavia, apoiando-nos na literatura dedicada ao debate relativo à política e à gestão educacional (COSTA, SZATKOSKI, 2015; BALL, 2011; BONDIOLI, 2004; SHIROMA, 2000), defendemos uma administração compartilhada em que o professor e os demais profissionais do ensino que atuam nas escolas e nas secretarias de educação, participem do processo de construção da docência em uma escola que se universalizou e que se tornou mais dinâmica e desafiadora. Apostamos, assim, num modelo de administração que viabilize " [...] a construção de uma escola autônoma, capaz de servir à cidadania, à democracia e à constituição de sujeitos de direitos [...]”. (COSTA, SZATKOSKI, 2015, p.167).

Assumindo a perspectiva de que as práticas administrativas têm implicações no modo como a escola universalizada se realiza nos diferentes contextos e constitui um importante 
mecanismo para a consolidação de uma proposta específica de Estado e de política pública, neste texto sistematizamos reflexões sobre a políticas de inclusão escolar em três municípios capixabas - São Mateus, Vitória e Vila Velha - , a partir dos saberes e das práticas dos profissionais que atuam nos setores de Educação Especial desses municípios.

Esses três municípios estiveram envolvidos na pesquisa intitulada "Políticas de acesso e de permanência de pessoas com deficiência no ensino comum: um estudo comparado de sistemas educativos brasileiros e mexicanos" que congregou trabalhos de pesquisadores brasileiros e mexicanos com o propósito de analisar a processualidade das políticas de acesso e de permanência de pessoas com deficiência no ensino comum. Desenvolvemos essa investigação em duas etapas complementares.

$\mathrm{Na}$ primeira etapa, cada grupo de investigadores (brasileiros e mexicanos) realizou, em seus países, contatos com diferentes órgãos, setores e instituições públicas dos municípios, foco do estudo, objetivando: mapear as legislações (municipais, estaduais e nacionais) que versam sobre a inclusão escolar de pessoas com deficiência; sistematizar dados censitários relativos ao acesso de estudantes com deficiência nos sistemas municipais envolvidos no estudo; analisar relatórios, resumos e/ou sínteses orçamentárias, projetos e/ou planos de trabalho que versassem sobre o financiamento da Educação Especial no âmbito dos municípios; identificar a existência de políticas articuladas, envolvendo diferentes setores públicos e/ou secretarias, que contribuíssem no processo formativo-educativo de pessoas com deficiência no ensino comum; caracterizar a estruturação e organização dos setores de Educação Especial nos sistemas municipais brasileiros e mexicano, envolvidos neste estudo. Os dados coletados nessa primeira etapa subsidiaram a elaboração de um roteiro para a realização de grupos focais, durante a segunda etapa desta investigação.

Assim é que, na segunda etapa, realizada entre abril e junho de 2015, constituímos grupos focais em cada município, objetivando maior aproximação ao campo pesquisado. Nesses grupos focais contamos com a participação de familiares de estudantes com deficiência matriculados no ensino comum, professores especialistas em Educação Especial, professores do ensino comum, diretores e pedagogos escolares e gestores dos setores de Educação Especial.

$\mathrm{Na}$ realização desses grupos focais, organizamos quatro eixos de discussão, a saber:

1. A escola como espaço de aprendizagem;

2. As oportunidades de aprendizagem vividas pelos estudantes com deficiência no ensino comum; 
3. Preocupações dos profissionais que atuam na administração pública relativas ao processo de concretização de uma escola para todos;

4. A dinâmica de intersetoralidade nos processos educativos de estudantes com deficiência.

Neste texto, reunimos discussões extraídas dos momentos dos grupos focais realizados nos municípios brasileiros - São Mateus, Vila Velha e Vitória - focalizando as percepções das profissionais que integram os setores de Educação Especial desses municípios, objetivando compreender como pensam e realizam a política educacional, tendo em vista o acesso e a permanência dos estudantes com deficiência nas escolas de ensino comum.

Os eixos de discussão que orientaram os debates nos grupos focais em articulação com o propósito deste texto, nos permitiram sistematizar os dados em seis categorias de análise, quais sejam:

1. A posição social do professor;

2. A instituição escolar como espaço social de aprendizagens;

3. A apropriação dos conhecimentos sociais pelos estudantes como ponto de partida para as politicas educacionais;

4. A relação: condições objetivas do trabalho docente e formação de professores.

5. O paradoxo: o diagnóstico e os investimentos político-pedagógicos nas escolas comuns.

6. O planejamento conjunto de ações entre setores públicos e secretarias.

Finalmente, destacamos que os dados foram discutidos a partir da literatura que versa sobre políticas e gestão educacional e estiveram apoiados em uma perspectiva históricosociológica que compreende que os seres humanos singulares se transformam nas interrelações, ao mesmo tempo em que transformam as inter-relações que eles constituem. Nessa abordagem sociológica, qualquer ação individual decorre de processos sociais em andamento. Desse modo, se por um lado, o indivíduo não pode ser pensado como reflexo ou "fruto", exclusivo, das coerções externas ou das forças sociais, por outro lado, nenhuma força social tem seu efeito nas decisões e escolhas dos indivíduos, fora da longa duração histórica. (ELIAS, 1994, 2001, 2005).

\section{Resultados}

Em cada município, iniciamos o grupo focal motivando os participantes a dialogarem sobre a seguinte afirmação: "A escola é o espaço de aprendizagem e de desenvolvimento. É uma instituição social em que as aprendizagens são obrigatórias”. 
Em São Mateus, a gestora 1 destacou sua compreensão de que o professor deve buscar aprender mais sobre suas práticas profissionais. Nesse sentido, para ela, a escola precisa ser percebida como um espaço de aprendizagem e de desenvolvimento para o aluno, mas também para o professor e para o pedagogo. Em outra parte do seu depoimento, ela se expressou da seguinte forma:

[...] quando um professor diz que às vezes chegam coisas que não são do nosso conhecimento, aí o que a gente faz? Corre atrás e busca aprendizagem porque somos sujeitos autônomos e somos responsáveis pelo nosso aprendizado [...]. (GRUPO FOCAL - SÃO MATEUS, ABRIL DE 2015).

Dialogando também sobre essa mesma afirmação inicial, durante o grupo focal realizado em Vitória, a gestora 4 disse-nos que considera muito importante desenvolver práticas de aprendizagens mais coletivas, aliada ao desejo de saber do professor.

[...] Você pode ter uma legislação linda, um currículo maravilhoso, todo mundo ali em volta, mas se o profissional que está diretamente ligado com aquilo ali não tem esse querer, não tem esse olhar de atender de perto cada um que está na sala, não funciona! [...] Então eu acho que precisa esse envolvimento geral. Do pensar coletivo em relação a aprendizagem. (GRUPO FOCAL EM VITÓRIA, MAIO DE 2015)

Também participando do debate relativo à afirmação inicial, no grupo focal realizado em Vila Velha, a gestora 5 chamou atenção para os vários desafios a serem enfrentados pela educação atual, destacando-se a necessidade da apropriação de conhecimentos e do encantamento do professor pela escola: “[...] eu acho que a educação tem milhões de desafios, nós estamos num período que eu acho que a gente tem que saber, eu acho que é importante trazer de novo esse encantamento, que a gente perdeu, de certa forma! [...]”. (GRUPO FOCAL EM VILA VELHA, MAIO DE 2015).

No debate, outra integrante do setor de Educação Especial do município de Vila Velha falou-nos de sua percepção de que o desafio da escola contemporânea é tornar-se um espaço prazeroso de aprendizagens. Ela problematizou:

[...] De que forma tornar isso realidade, potencializar esse espaço, mas de que forma podemos manter essa aprendizagem? [...] Estava lendo um texto, uma reflexão em que o autor falou: 'Dizem que os nossos alunos são do século XXI, os professores são do século XX e as escolas são do século XIX'. Aí você vê as coisas que estão vendo, então, como tornar esse processo prazeroso, tanto para o professor como para o aluno? (GESTORA 6, GRUPO FOCAL EM VILA VELHA, MAIO DE 2015)

As declarações dessas profissionais evidenciam que, crescentemente, a escola vem sendo compreendida como lugar privilegiado de socialização de saberes e local onde se 
ampliam as relações humanas, por meio da apropriação do conhecimento. Com efeito, as relações laborais estabelecidas em contexto ocupados no processo de aprendizagem criam marcas na trajetória de cada pessoa em particular. Afinal, a pessoa se desenvolve, também, no interior da sua ocupação profissional que, por sua vez, encontra-se em permanente movimento de ressignificação num marco conjuntural específico. Por isso, acreditamos que a posição social do professor que atua na Educação pública precisa ser tomada como uma das inúmeras posições sociais constitutivas das atividades estatais e em articulação com elas. $\mathrm{Na}$ nossa perspectiva, esse poderia ser o marco de referência para o debate sobre a necessidade de "[...] trazer de novo esse encantamento" do professor pela escola, tornando-a "[...] um espaço prazeroso de aprendizagens".

De fato, se desejamos escapar à prática de individualizar culpas e erros, quando apostamos na escola como espaço social de aprendizagem e de desenvolvimento humano, precisamos problematizar o trabalho docente em conexão com aspectos mais amplos da conjuntura que torna possível e, muitas vezes, até necessário a explicitação de resistências ou de um certo "não querer saber" pelo professor.

Nesse sentido, vale considerar que as recentes reformas educacionais de cunho economicista, fundamentada na desqualificação das atividades estatais em detrimento da hipervalorização das "boas" práticas gerenciais dos setores privados, tendo em vista sua transposição para as instituições públicas, faz mais do que subjugar e restringir a atuação profissional daqueles que trabalham na administração pública. Envolve e afeta a pessoa ocupante dessa posição social. Essa perspectiva economiscista e gerencialista também fragiliza a capacidade das pessoas para seguir códigos profissionais e até mesmo para lidar com frustrações e tensões que decorrem do trabalho docente na escola universalizada.

Abordando essa questão, Costa e Szatkoski (2015, p. 167) nos parecem bastante elucidativos ao afirmarem que "[...] um dos principais problemas enfrentados pelo professor é não se sentir participante do processo de construção da docência [...]”. Na mesma direção Nóvoa (1999, Apud COSTA; SZATKOSKI, 2015, p. 165) nos alerta que o professor necessita alargar sua autonomia na constituição de sua própria profissão, inclusive em conexão com os demais trabalhadores da educação.

Desse modo, acreditamos que os gestores do setor de Educação Especial e suas equipes precisam encarar o desafio de reiterar a pertinência da atividade estatal, assumindo a escola pública como espaço de materialização dos direitos sociais e, portanto, de realização humana. Essa atuação demanda reflexões aprofundadas e mais sistemáticas sobre a posição 
social do professor tomando-a como uma das inúmeras posições sociais constitutivas das atividades estatais.

Transitando do âmbito individual para o âmbito coletivo, as gestoras reiteram a pertinência da busca pela aprendizagem em estreita vinculação com o coletivo. Focalizam a importância da iniciativa individual na busca pelo saber que poderá auxiliar na solução de questões e de demandas que emergem no cotidiano da escola comum. Esse aspecto nos provoca destacar que a instituição escolar, como espaço social de aprendizagens, tem demandado dos profissionais um saber cada vez mais ampliado sobre a vida em sociedade. Nessa direção, Shiroma e Evangelista (2003) advogam a necessidade de considerar que os discursos presentes nas reformas políticas dos anos de 1990 trouxeram pontos de valorização pessoal e financeira para o professor e, ao mesmo tempo, estabeleceram novos referenciais para o trabalho docente.

Embora não seja uma tarefa fácil para aqueles que atuam na administração pública municipal nesse momento de reformas políticas engajadas na reconfiguração da atuação do Estado, acreditamos que os integrantes dessas equipes devam investir na garantia de espaços coletivos de estudo e de debates em contexto que ajudem os profissionais do ensino a compreenderem o processo de produção do conhecimento e as condições sociais do uso dos saberes que subsidiam seu trabalho profissional. Esse processo pode nos ajudar a perceber as riquezas e os limites dos saberes constituídos socialmente, de modo que, ao recusá-los ou ao aceitá-los, inclusive ressignificando-os, o façamos com conhecimento de causa.

A segunda questão apresentada nos grupos focais dizia respeito às possibilidades e às oportunidades de aprendizagem vividas pelos estudantes com deficiência no ensino comum.

As declarações dos participantes indicam que nas três realidades municipais pesquisadas, os docentes têm vivido experiências de colaboração e de construção coletiva nas práticas pedagógicas. Focalizando a dinâmica da sala de aula, a gestora 1 destacou a importância do trabalho colaborativo e, particularmente, da intervenção que o professor da sala de recursos pode fazer junto ao professor do ensino comum.

[...] alguns professores conseguiram olhar para o aluno e pensar em possibilidades de aprendizagem, e isso veio, exatamente, a partir do trabalho colaborativo. Veio a partir dessa intervenção que o professor da sala de recursos faz junto ao professor do ensino regular. Eu continuo acreditando que essa é a linha que a gente precisa caminhar. A gente precisa, na verdade, ter mais tempo para que o professor da sala de recursos esteja intervindo com o professor do ensino regular. (GRUPO FOCAL EM SÃO MATEUS, ABRIL DE 2015). 
De toda forma, embora perceba melhorias no oferecimento de oportunidades de aprendizagem para os estudantes com deficiência, ela considera fundamental sustentar a mudança na prática do professor, o que, em sua opinião, pode acontecer por meio da formação continuada.

Hoje eu vejo com muita satisfação o avanço que a gente já conseguiu. Mas nesses anos, a gente vem fazendo alguns diagnósticos e, em minha opinião, mais minha do que do resto da equipe... começar a mudar a prática do professor, para começar a mudar essa realidade, e aí a gente precisa de formação continuada. Em minha opinião, o viés que a gente precisa para conseguir alcançar o professor, mostrar para ele que é possível, é formação continuada. (GRUPO FOCAL EM SÃO MATEUS, ABRIL DE 2015).

No grupo focal realizado em Vitória, os participantes empenharam-se em debater as possibilidades educativas dos estudantes com deficiência, destacando a necessidade de os profissionais do ensino investirem pedagogicamente nesses estudantes. Nesse debate, a gestora 4 destacou o fato de que o professor de ensino comum está muito sobrecarregado. Acompanhando as indicações de outros participantes, ela ressaltou que a dinâmica da sala pode ser mais qualificada, se o professor do ensino comum puder contar com o trabalho de outros profissionais da escola. Também reiterou que a construção de melhores oportunidades de aprendizagem para estudantes com deficiência, decorre da organização de formações para os professores do ensino comum.

[...] eu acho que é fundamental o acompanhamento de mais profissionais, de estagiários na sala de aula de ensino comum, [...] a gente sabe o quanto faz diferença ter um apoio em sala, né, porque o menino está alí, e você tem que atender e não tem como! A gente tem toda uma legislação, agora faltam investimentos [...] o professor já fica muito sobrecarregado. Eu sempre falo assim, quando tudo falha, dá errado, se o estagiário faltou, se a escola está com problema, sobra paro o professor de sala, que tem aquela criança e mais o restante da turma né, então eu acho que é uma questão que tem que se pensar, eu acho que a gente tem, sim, uma carência de pessoal, e essa carência também é de formação [...]. (GRUPO FOCAL EM VITORIA, MAIO DE 2015).

Assim, articulado às questões de formação, durante os grupos focais realizados nos três municípios, as condições objetivas do trabalho docente assumiam centralidade nas preocupações e nas questões levantadas pelas gestoras. A declaração da gestora 6, que atua no município de Vila Velha, pareceu-nos representativo dessa preocupação.

[...] a gente tem que pensar nesse professor, porque eu cobro dele uma polivalência, mas eu sou especialista, então a gente tem que saber que são processos, e eu vejo muito professor vestindo a camisa e muito pedagogo vestindo a camisa, muito mais do que a gente, tem hora [...] então a gente já vê também que existe frutos interessantes, de pedagogos já questionando e colaborando com o trabalho também da gente, entendeu? Que não é fácil, quando a gente fala de inclusão, a gente fala do 
professor de Educação Especial, de professor regente, de tudo desse aluno [...]. (GRUPO FOCAL EM VILA VELHA, MAIO DE 2015).

Referindo-se às condições objetivas que impactam mais diretamente no trabalho docente tendo em vista a inclusão escolar, a gestora 3 considera importante que o município de Vitória efetue novos investimentos em espaços físicos, nas formações e na valorização profissional.

[...] A acessibilidade nos espaços físicos deve ser considerada, porque a gente ainda lida com a questão de não ter acessibilidade em todos os espaços. Formação continuada e espaços-tempos para discussões. Muitas vezes elas são organizadas em horário e local que inviabiliza a participação das pessoas. [...] Aí a gente solicita a garantia de que haja investimentos nos espaços físicos, no trabalho pedagógico, nas formações, nos diálogos, nos fazeres, nos tempos. E a valorização da força de trabalho, que a gente trabalha. Então a gente quer assim ser valorizado pelo trabalho que a gente faz [...]. (GRUPO FOCAL EM VITÓRIA, MAIO DE 2015).

Do que apontam as gestoras e no que se refere à garantia de oportunidades de aprendizagem para os estudantes com deficiência matriculados no ensino comum, os desafios apresentados demandam a elaboração de políticas públicas, cujas diretrizes representem o ponto de partida, evitando-se o engessamento e a estruturação a priori dos serviços, projetos e programas educacionais.

É fundamental considerar que, via de regra, as políticas definidas na instância central do sistema seguem uma padronização que não atendem às demandas locais ao passo que "[...] quase sempre, chegam a desconsiderar a necessária contribuição daqueles que irão operá-las" (COSTA; SZATKOSKI, 2015, p.172). Nesse sentido, acreditamos que as diferentes necessidades e demandas dos estudantes, identificadas pelos profissionais da escola, precisam se constituir em balizadoras da disponibilização de recursos, de materiais, bem como, para a localização de outros profissionais nas unidades de ensino pelas secretarias municipais de educação. Vale reiterar que nem sempre, os estudantes demandam os mesmos recursos, os mesmos tempos e as mesmas condições de aprendizagem. Nesse sentido, condicionar o funcionamento da escola às prerrogativas e disposições gerais do sistema pode ser danoso ao processo inclusivo desses estudantes, além de dificultar o trabalho docente e o diálogo mais propositivo da administração pública com a comunidade local.

Mas, é importante destacar que não estamos defendendo a extinção de um planejamento e de um acompanhamento sistemático pelos setores de Educação Especial às atividades realizadas pela escola. Estamos, tão somente, assumindo a premissa de que o fim da prática educativa escolar é a apropriação dos conhecimentos sociais pelos estudantes. 
Nesse sentido, os setores de Educação Especial precisam contribuir para que a escola alcance sua pretensão fundante: a apropriação do saber escolar pelos estudantes com deficiência. As questões apontadas durante os grupos focais, nos motivam ressaltar que à coordenação dos setores de Educação Especial cabe o importante exercício crítico e reflexivo a respeito do fato de que uma escola para todos se faz com todos e partir de todos. Nesse aspecto, há que considerar as experiências vividas na avaliação das políticas e das propostas educativas que se vem implementando. Sem a referência àquilo que se fez e àquilo que se realiza na escola, continuaremos a tomar as possibilidades como um eterno vir a ser enquanto os desafios e tensões serão, via de regra, sempre tomados como a justificativa para o não fazer.

Falamos da busca por um Estado democrático, que somente poderá ser alcançado efetivamente na medida em que vivenciarmos relações democráticas nas quais “[...] o direito de dizer, o que equivale ao dever da escuta atenta, seja tão necessário quanto imperioso para a construção da política educacional”. (COSTA; SZATKOSKI, 2015, p.170).

Nas declarações das gestoras também identificamos que a formação profissional dos professores se configura em processos iniciais e continuados imbricados. Acrescenta-se a essa indicação, nossa perspectiva de que a formação continuada é um processo pelo qual os sujeitos estabelecem relações entre si e com o conhecimento na vida cotidiana. Se assumirmos o conhecimento como um fato indiscutível que tem como características ser prático, social e histórico, conforme nos aponta Lefebvre (1995), a formação continuada precisa ser observada como ato político e, quando articulada à formação inicial, pode contribuir significativamente no trabalho das agências formadoras e das equipes que atuam na administração dos sistemas de ensino.

Nesse debate, parece pertinente destacar nossa defesa de que a formação inicial é primordial na constituição profissional e a formação continuada deve vincular-se a ela por meio da concretização do fazer pedagógico. Nesse sentido, não se trata de considerar a formação continuada como uma complementação da formação inicial, que responda às suas "lacunas", menos ainda como uma ação que venha supri-la. Para nós, a formação inicial e a formação continuada constituem faces distintas e complementares do processo profissional.

Analisando as declarações, observamos que, reiteradamente, as gestoras destacam a dimensão coletiva e colaborativa do trabalho docente. Argumentam sobre a necessidade de “[...] mais tempo para os professores da sala de recursos estarem intervindo com o professor do ensino regular $[\ldots]$ ” e percebem que "[...] o professor já fica muito sobrecarregado [...]". 
Essas questões evidenciam que o funcionamento da escola universalizada constitui preocupação para um grupo cada vez maior de pessoas e o trabalho docente tem sido considerado recorrentemente e em diferentes perspectivas.

Em articulação com a indicação dos gestores de que o trabalho colaborativo e a formação continuada podem se constituir “[...] no viés para conseguir alcançar o professor [...]", destacamos que esses dois aspectos precisam se configurar como convite ao diálogo e à reflexão sobre a escola, sua política interna e o seu funcionamento. Ouvir o que os professores têm a dizer é imperativo nessa direção. Assim, em se tratando de formação continuada, talvez, antes de enumerar grandes temas, ou antes, de debater sobre o estudante que "não aprende na escola", outras questões estruturais e materiais, ou questões relativas ao conteúdo escolar, poderiam estar na pauta de questões mais imediatas para o professor. Nesse sentido, considerar os fatores objetivos que influenciam diretamente o trabalho docente poderia ser uma tônica da formação continuada de professores a ser exercitada nos diferentes sistemas municipais de ensino.

Em outro momento do grupo focal fizemos a seguinte solicitação: "Comente sobre as principais preocupações dos profissionais que atuam na administração pública. Relate experiências marcantes que mostram como o Poder Público Municipal pode participar no processo de concretização de uma escola para todos".

No encontro realizado em São Mateus, a gestora 1 informou-nos que, em atendimento às demandas da Secretaria de Educação e acreditando na possibilidade de mudar a realidade da Educação Especial, o setor propôs uma formação de professores para o ano de 2015. Porém, outras tensões emergiram nesse processo.

[...] esse ano, a gente propôs uma formação continuada, na modalidade de estudo. Não de 'vim para pegar respostas', mas vim para sentar, juntar: vamos estudar, vamos pensar, é assim mesmo? [...] e, infelizmente, eu fiquei triste porque quando a gente lançou a formação, a gente pensou em duas turmas de professores do $6^{\circ}$ ao $9^{\circ}$ ano, porque o nosso gargalo está do $6^{\circ}$ ao $9^{\circ}$ ano. Mas nós não conseguimos fechar nenhuma turma de professores do $6^{\circ}$ ao $9^{\circ}$ ano. Eu, simplesmente, fiquei triste... não só eu, mas todo setor de formação, porque também é um diagnóstico deles. Então, como trazer esse professor para a formação? É uma pergunta que eu coloco aqui: como trazer esse professor, como despertar nele o desejo em aprender? Para que a gente possa mudar a realidade da Educação Especial.

Nos relatos e nos comentários feitos, observamos que os serviços de Educação Especial no contexto da escola de ensino comum constituem parte importante no trabalho do setor de Educação Especial. Relataram que, em algumas ocasiões, têm que ir às escolas para reiterar algumas atribuições dos professores especialistas naquele contexto. Em diferentes 
oportunidades, encontram escolas e professores se destacando na proposta do trabalho com o estudante público alvo da Educação Especial. No grupo focal realizado em Vila Velha, por exemplo, a gestora 6 se expressou nos seguintes termos:

[...] a gente vê que tem escola que também vem fazendo um trabalho muito interessante, mesmo assim é um trabalho que não é fácil porque as escolas não têm estrutura. Eu falo estrutura, eu falo de espaço, eu falo de tudo, né, de estrutura, do reconhecimento profissional, financeiro, né, uma coisa assim, o reconhecimento, [...] eu acho que tem professores dando um banho [...]. (GRUPO FOCAL EM VILA VELHA, MAIO DE 2015).

Nesse sentido, as gestoras acreditam na importância de o setor de Educação Especial articular-se com a escola para qualificar os processos educativos. A esse respeito, continua a gestora 6:

[...] Tem que ter um envolvimento até da secretaria também, qualificando esses profissionais, a gente tem esse papel também, de estar nas escolas potencializando, porque não é fácil, e de que forma? Eu acredito muito em formação e na informação [...]. (GRUPO FOCAL EM VILA VELHA, MAIO DE 2015).

Participando do debate realizado em São Mateus, a gestora 1 relatou-nos a dinâmica de trabalho que realiza junto às escolas municipais:

[...] A gente vem orientando em relação a isso, com relação à legislação, com relação à adaptação curricular, com relação a olhar o aluno na sua individualidade, na sua especificidade. E eu posso dizer com firmeza que o que a gente conseguiu até hoje foi com o trabalho das professoras das salas de recursos. (GRUPO FOCAL EM SÃ̃O MATEUS, ABRIL DE 2015).

Para os gestores, algumas dificuldades poderiam ser superadas com um maior engajamento dos próprios professores especialistas que atuam nas escolas. A gestora 6, que atua em Vila Velha, contribuiu nesse debate.

[...] eu vejo muitas pessoas muito engajadas, lógico que a gente tem casos que a gente até assusta, alguns professores que ligam pra gente e falam bem assim: olha vem cá que a professora de Educação Especial não sai daquela sala de recursos, levou o computador para lá e lá ficou, acabou. A gente escuta muito isso, aí a gente vai à escola e conversa com o professor especialista até pra ele saber qual é o papel deles na escola e refletir se eles estão incluindo os alunos ou se eles estão excluindo os alunos. (GESTOR 6, GRUPO FOCAL EM VILA VELHA, MAIO DE 2015).

Do ponto de vista de sua atuação, essa gestora declarou:

Agora, eu penso também, assim, enquanto setor de Educação Especial, que a gente ainda tem muita coisa para avançar: questões de legislação, questão de acompanhamento clínico, porque, às vezes, a gente embarra numa situação clínica, que precisa desse acompanhamento. (GRUPO FOCAL EM SÃO MATEUS, ABRIL DE 2015). 
Observamos que não diferente desses três municípios, a questão da avaliação e do diagnóstico associados ao acompanhamento clínico, têm sido apontado como um dos impasses significativos na atuação dos setores de Educação Especial em muitos municípios brasileiros. Mesmo que tenhamos avançado em relação à política de garantia do direito à escolarização da pessoa com deficiência, a partir da publicação de legislações específicas, o caráter médico-clínico continua tendo força e influência nas decisões político-pedagógicas nas escolas comuns. Vivemos um paradoxo, se por um lado não especificarmos as peculiaridades do aluno público alvo da Educação Especial para não rotulá-lo, corremos o risco do seu apagamento e de sua invisibilidade na vida cotidiana escolar, bem como nos necessários investimentos das políticas públicas. Por outro lado, quando especificamos quem é o sujeito e quais são suas peculiaridades, corremos o risco de sujeitá-lo a determinados limites de investimentos político-pedagógicos, atribuindo à perspectiva clínica a única possibilidade de intervenção. Esse é um dilema importante a ser considerado pela administração pública municipal, pela via das equipes que atuam no setor de Educação Especial.

As declarações desses gestores evidenciam que a ampliação do conhecimento relativo à educabilidade das pessoas com deficiência, no decorrer do século passado, tem contribuído para uma maior compreensão sobre o processo educativo dessas pessoas nos anos recentes, principalmente quando consideramos a vida em sociedades complexas como as nossas. Assim, um número cada vez maior de pessoas vislumbra processos sociais fundamentados numa expectativa de que todos podem e devem usufruir de um conjunto de direitos sociais, entre eles, o direito à escolarização.

Desse modo, tornou-se lugar comum a crença de que a escola se configura atualmente como uma das principais instituições capazes de inserir os sujeitos no mundo e na cultura. Assim é que, por meio de diagnósticos feitos junto aos professores, os gestores do município de São Mateus perceberam a necessidade de promover espaços formativos mais sistemáticos que qualifiquem a atuação docente. Também do ponto de vista das equipes que atuam no setor de Educação Especial, os profissionais do ensino demandam conhecimento relativos “[...] à legislação, [...] à adaptação curricular [...]" e "[...] com relação a olhar o aluno na sua individualidade, na sua especificidade".

Finalmente, pedimos que os participantes falassem sobre a dinâmica de intersetoralidade nos processos educativos de estudantes com deficiência matriculados no ensino comum. A esse respeito, os gestores destacavam algumas intervenções que precisam 
ser realizadas pela administração pública municipal. No grupo focal, realizado em Vitória, a gestora 4 declarou:

[...] A articulação intersetorial: a gente de novo fala da fragilidade e aí a fragilidade vem pela fragmentação. Cada quadrado cuidando do seu e a hierarquização, e nessa hierarquização então a gente tá por baixo [...] a gente fica correndo atrás com a política do pires na mão pedindo pra articular alguma coisa, a gente percebe isso. (GRUPO FOCAL EM VITORIA, MAIO DE 2015).

Em Vila Velha, comentaram sobre ausência de políticas mais articuladas entre setores e secretarias,

[...] Com a ausência de articulação entre os setores, com a ausência de viabilizar recursos mais específicos que a educação especial necessita. O menino, o aluno de educação especial, ele não vai ter o desenvolvimento dele proporcionado apenas com o atendimento pedagógico na escola. Esse menino precisa potencializar o desenvolvimento cognitivo com terapia clínica, com fonoaudiologia, fisioterapia, com estimulação precoce, são uma série de serviços que deveriam ser ofertados pelo Estado, em paralelo a educação, não sei se pela Secretaria de Saúde, se pela Secretaria de Ação Social, isso aí independe, mas são serviços que apoiam o processo de inclusão nas escolas. (GRUPO FOCAL EM VILA VELHA, MAIO DE 2015).

No grupo focal realizado em São Mateus, a gestora 1 destacou algumas mudanças nas articulações internas na Secretaria Municipal de Educação o que tem ocasionado melhorias no trabalho junto aos estudantes com deficiência.

[...] o meu questionamento com relação ao poder público é que as coisas ainda são muito morosas. Tudo demora muito pra chegar na escola. E isso precisa mudar, né? Minha avaliação é que a gente já conseguiu mudar algumas questões nesse sentido. Por exemplo, a articulação dentro da Secretaria de Educação já melhorou, eu diria $80 \%$. [...] Então quando a gente começa a ter essa articulação com os outros setores as coisas começam a chegar na escola. [...], a inclusão perpassa a escola, mas perpassa também os órgãos públicos. Porque o setor precisava ser incluído junto com os outros, ainda, né. Hoje a gente já conseguiu alcançar isso, mas ainda há morosidade na oferta dos serviços públicos. (GRUPO FOCAL EM SÃO MATEUS, ABRIL DE 2015).

A questão colocada possibilitou que essas profissionais comentassem sobre suas expectativas e percepções relativas ao papel do Estado na garantia de qualidade na escolarização ofertada para os estudantes com deficiência. Atuando na esfera governamental num momento em que se tem aprofundado e ampliado a centralidade da esfera econômica nos encaminhamentos administrativos e políticos do Estado, elas experimentam, em muitas situações, as fortes marcas do clientelismo, do patrimonialismo, aliada, muitas vezes, à precariedade crescente do serviço público que narram o funcionamento da "máquina estatal".

Atuando na administração pública municipal, elas avaliam que, via de regra, as demandas específicas dos indivíduos e suas necessidades não se constituem em balizadores 
decisivos para a operacionalização de espaços e de serviços que garantam a "[...] igualdade de condições para o acesso e permanência na escola [...]" (art. 3º I, LDBN nº 9.394/96), bem como “[...] currículos, métodos, técnicas, recursos educativos e organização específicos, para atender às suas necessidades" (art. 58, I, LDBN n 9394/96) e ainda "[...] acesso igualitário aos benefícios dos programas sociais suplementares disponíveis para o respectivo nível do ensino regular" (art.58, V, LDBN n 9.394/96).

Vivenciando esses dilemas, outras demandas se colocam na implementação das políticas educacionais, ganhando destaque a crescente preocupação em organizar ações articuladas entre setores públicos e/ou secretarias municipais no oferecimento de serviços e de espaços qualificados às necessidades especiais dos estudantes com deficiência.

Pintor, Júnior e Costa (2012, p. 206) nos permitem compreender a constituição dessa política, como uma prática intersetorial. De acordo com esses autores, a intersetorialidade é “[...] a articulação de saberes e experiências no planejamento, realização e avaliação de ações para alcançar efeito sinérgico em situações complexas visando o desenvolvimento social, superando a exclusão social" (PINTOR, LHERENA JÚNIOR; COSTA, 2012, p.206). Assim, a intersetorialidade pressupõe a articulação entre os setores públicos contribuindo para que o trabalho das secretarias alcance uma parcela maior da sociedade. Sem eliminar a importância de espaços específicos de atuação nas políticas setoriais,

[...] o ponto forte da proposta de intersetorialidade é a possibilidade de se construir uma visão de complexidade dos problemas tendo como requisito o aporte de diferentes acúmulos setoriais. Trata-se, pois, de construir objeto e objetivos comuns, o que difere das propostas que se traduzem na mera sobreposição ou justaposição de ações setoriais [...]. (MONNERA; SOUZA, 2009, p. 208).

Considerando essa especificidade das políticas intersetoriais, outros desafios teóricos e práticos estão colocados às equipes dos setores de Educação Especial. Se por um lado, os profissionais que atuam nesses setores necessitam formular e implementar ações que minimizem as iniquidades sociais, contribuindo para uma melhor qualidade de vida dos estudantes com deficiência, por outro lado, esses profissionais precisam investir em estudos e debates que lhes possibilitem "[...] romper com a tradição da ciência moderna, que opera com uma lógica parcializada de organização e produção do saber, tendo como consequiência uma intensa especialização disciplinar e práticas sociais fragmentadas [...]”. (MONNERA; SOUZA, 2009, p. 204). 


\section{Considerações finais}

A perspectiva de Estado neoliberal vem impactando as democracias modernas e consolidando a adoção da lógica economicista na administração das políticas sociais. Do ponto de vista das teorias da administração, trata-se da adoção de modelos neo-tayloristas com fortes marcas do gerencialismo. Nessa perspectiva administrativa, os pressupostos do liberalismo econômico e político são colocados em ação sob outras roupagens. Adotando mecanismos de controle da "máquina pública" e condicionando o Estado ao papel de mero executor e legitimador da lógica do Mercado, recorrentemente, a sociedade civil é convidada à participação, à colaboração e ao engajamento político. Entretanto, erigindo-se no escopo da administração neo-taylorista, essa participação civil atende a indicativos muito evidentes que, ao seu modo, reúne condições de aferir qualidade nas atividades e nos serviços públicos estatais. Entre outras indicações, sugere que o usuário/cliente cuide da avaliação e do acompanhamento desses serviços. Associando e submetendo a dinâmica social aos ditames da competitividade e da meritocracia, por esse viés economicista e gerencialista, as políticas públicas são pensadas, essencialmente, como gastos de recursos, de modo que a relação custo-benefício é a mola propulsora dos investimentos estatais.

Constituindo esse processo de reformas políticas vividas em território brasileiro no curso dos últimos anos do século $\mathrm{XX}$ e da primeira década do século XXI, as práticas administrativas dos setores de Educação Especial nos três municípios envolvidos nesta pesquisa, trazem intencionalidades políticas para a melhoria das condições de realização da educação de pessoas com deficiência. Contudo, o contexto onde operam essas ações encontrase imerso na disciplina de mercado ${ }^{6}$, com fortes ressonâncias em outras dimensões da vida em sociedade, evidenciando inúmeros desafios políticos e sociais, especialmente para aqueles/as que atuam na administração pública e que compreendem a escola como espaço de aprendizagem para todos.

Entre esses desafios destaca-se a necessidade de superar perspectivas administrativas centralizadas que, de fundo, retiram da escola e de seus profissionais, principalmente daqueles que atuam nas equipes de administração escolar, a possibilidade do exercício de uma prática

\footnotetext{
${ }^{6}$ De acordo com Wouters (2009), durante o século XX, a existência social passou a ser delineada pela disciplina de mercado. A intensificação dessa disciplina de mercado influenciou outras esferas da vida, inaugurando uma etapa mais avançada de monetarização das relações sociais. Assim, nos países ocidentais industrializados, paulatinamente, o mercado constituiu-se como espaço de realização pessoal.
} 
educativa escolar qualificada às demandas dos estudantes com deficiência.

Nesse debate é importante ter em vista que os padrões administrativos gerenciais altamente centralizados colocados em ação pelas instâncias estatais, inclusive aquelas que assumem o "Modelo de Excelência em Gestão Pública", apresentam fortes antagonismos nos processos de inclusão anunciados pela política pública. Se por um lado avançamos na proclamação e identificação dos direitos sociais das pessoas com deficiência, por outro ainda nos faltam condições para que esse direito se materialize. Essas modelos de gestão pública parecem atuar muito mais no sentido de administrar as desigualdades educativas, do que minimizar e superá-las efetivamente.

Em vista disso e considerando o propósito deste texto, importa destacar que uma administração centralizada dos processos escolares, via sistema de ensino, não favorece um diálogo mais próximo com o professor. Em outros termos, não nos parece possível concretizar a escola para todos, quando um grupo ou uma pequena parcela da sociedade toma para si a administração (e o controle) dos progressos de todo esse processo inclusivo, que é dinâmico e complexo, porque é social.

Nesse sentido, os dados e as reflexões que vimos desenvolvendo subsidiam nossas defesas em torno de uma administração descentralizada e compartilhada, com conotações e desdobramentos mais democráticos.

Assumir essa perspectiva administrativa mais democrática implica, entre outras questões, reunir esforços teóricos e práticos que auxiliem na realização de formação continuada para os profissionais do ensino, cujos temas e estudos respondam mais adequadamente às demandas do professor, visto como pessoa numa ocupação profissional específica que somente tem sentido na articulação e em conexão com as outras ocupações profissionais dentro da própria administração pública estatal. Por isso, vale dizer, observamos a premência de os profissionais que atuam nos setores de Educação Especial investirem na instituição de espaços coletivos de formação que também instrumentalizem e impulsionem reflexões mais profundas sobre a escola e sua intencionalidade política, sobre a sociedade e sobre o conhecimento.

Assumida no ideário do Estado democrático que assegura a educação escolar como direito público subjetivo, essa perspectiva administrativa caminharia no sentido de construir indicadores que auxiliem na reorientação das políticas, dos programas e das ações estatais. Nesses indicadores, a apropriação do conhecimento social, os sujeitos e suas demandas, 
figurariam como ponto de partida e como ponto de chegada das práticas e das políticas públicas, desenvolvida nos sistemas e nas escolas.

\section{Referências}

ARRUDA, Ana Lúcia Borba de; NÓBREGA, Cristiane Liberato da. Planejamento educacional e a "modernização da gestão educacional em Pernambuco: alguns apontamentos. Revista Brasileira de Política e Administração da Educação, v. 29, nº 32, p. 525-536, set/dez. 2013.

BALL, Stephen J. Intelectuais ou técnicos? O papel indispensável da teoria nos estudos educacionais. In: BALL, Stephen J.; MAINARDES, Jefferson (Org.). Políticas educacionais: questões e dilemas. São Paulo, SP: Cortez, p. 78-99, 2011.

BONDIOLI, A. O projeto pedagógico da creche e a sua avaliação: a qualidade negociada. Campinas, SP: Autores Associados, 2004.

BRASIL. Lei $n^{\circ}$ 9.394, de 20 de dezembro de 1996. Estabelece as Diretrizes e Bases da Educação Nacional. Brasília: Diário Oficial da União [da] República Federativa do Brasil, 23 dez. 1996.

Ministério do Planejamento, Orçamento e Gestão. Secretaria do Planejamento.

Programa Nacional de Gestão Pública e Desburocratização - GESPÚBLICA. Documento 1. Instrumento para Avaliação da Gestão pública- Ciclo 2006. Brasília: MPOG, 2006.

COSTA, Daianny Madalena; SZATKOSK, Luciane. Possibilidades de avanço democrático a partir das políticas educacionais: olhares sobre a gestão municipal de Jacareí. Revista Brasileira de Política e Administração da Educação, v. 31, n. 1, p. 159 - 175 jan./abr. 2015.

CURY, Carlos Roberto Jamil; FERREIRA, Luiz Antonio Miguel. Obrigatoriedade da educação das crianças e adolescentes: uma questão de oferta ou de efetivo atendimento? Nuances: estudos sobre Educação. Ano XVII, v. 17, n. 18, p. 124-145, jan./dez. 2010.

ELIAS, N. O processo civilizador. 2. ed. Rio de Janeiro: Jorge Zahar,1994.

A sociedade de corte: investigação sobre a sociologia da realeza e da aristocracia de corte. Rio de Janeiro: Jorge Zahar, 2001. Introdução à sociologia. Lisboa: Edições 70 LTDA, 2005.

LEFEBVRE, Henri. Lógica formal, lógica dialética. 6. ed. Rio de Janeiro, RJ: Civilização Brasileira, 1995.

MONNERA, Giselle Lavinas; SOUZA, Rosimary Gonçalves de. Política social e intersetorialidade: consensos teóricos e desafios práticos. SER Social, Brasília, v. 12, n. 26, p. 200-220, jan./jun. 2009. 
PINTOR, Nelma; LHERENA JUNIOR, Juan Clinton; COSTA, Valdelúcia Alves. Educação e saúde: um diálogo necessário às políticas de Atenção Integral para Pessoas com Deficiência. Rev. Educ. Espec., Santa Maria, v. 25, n. 43, p. 203-216, maio/ago. 2012.

SARMENTO, Dirléia Fanfa; MENEGAT, Jardelino; RAMIREZ, Vera Lúcia. Educação de qualidade e gestão pública: a construção do planejamento de uma secretaria de Educação. Revista Brasilera Política e Administração da Educação, v. 31, n. 2, p. 313 - 333 maio/ago. 2015.

SHIROMA, Eneida; Oto, MORAES; Maria Célia Marcondes de, EVANGELISTA, Olinda (Org.). Política educacional. Rio de Janeiro, RJ: DP\&A, 2000.

WOUTERS, Cas. Mudanças nos regimes de costumes e emoções: da disciplinarização à informalização. In: GEBARA, Ademir; WOUTERS, Cas. (Org.). O controle das emoções. João Pessoa, PB: Editora Universitária da UFPB, 2009. p. 91-117. 